\title{
La búsqueda del Yo y el desarrollo de la personalidad en el "diario de Gilleleje” de Søren Kierkegaard
}

\author{
NASSIM BRAVO* \\ Universidad Panamericana (México) \\ fbravo@up.edu.mx
}

\begin{abstract}
Resumen
En el siguiente artículo se ofrece un análisis del denominado "diario de Gilleleje" del filósofo danés Søren Kierkegaard. Se intenta argumentar que en este escrito temprano de 1835 y de un carácter eminentemente literario es posible encontrar las reflexiones filosóficas incipientes de un joven Kierkegaard acerca de la cuestión existencial del descubrimiento del propio Yo y la construcción de la personalidad, uno de los temas fundamentales en la obra del escritor danés. El desarrollo del texto culmina con la exposición de uno de los conceptos claves del pensamiento kierkegaardiano: la verdad subjetiva.
\end{abstract}

Palabras clave: Kierkegaard; individuo; subjetividad; verdad subjetiva; Bildungsroman.

\section{The search for the Self and the development of personhood in Soren Kierkegaard's "Journal of Gilleleje"}

\begin{abstract}
In the following article I offer an analysis of the so-called "journal of Gilleleje" by Danish philosopher Soren Kierkegaard. I would like to argue that in this early writing of 1836, a piece with a distinct literary tone, it is possible to observe young Kierkegaard's first philosophical insights on the existential question about the discovery of the self and the development of personhood, one of the key topics in the Dane's writings. The journal concludes with the exposition of a central concept in Kierkegaard's thought: subjective truth.
\end{abstract}

Key words: Kierkegaard; individual; subjectivity; subjective trutb; Bildungsroman.

\footnotetext{
* Doctor en Filosofía (Universidad Nacional Autónoma de México). Profesor investigador de tiempo completo en el Departamento de Humanidades de la Universidad Panamericana, campus Aguascalientes (México). Ha traducido varias obras de Søren Kierkegaard del danés al castellano. Por ejemplo: Diarios. Volumen III (2015), Diarios. Volumen IV (2015) y Diarios. Volumen V (2016). También tradujo la biografía de Kierkegaard escrita por Alastair Hannay, Kierkegaard: Una biografía (2010). Ha publicado artículos como "The Master-Thief: A One-Man Army against the Established Order" (2014), "Nicolaus Notabene: Kierkegaard's Satirical Mask" (2014) y "La comedia especulativa como crítica social. Johan Ludvig Heiberg y 'Un alma después de la muerte" (2018).
} 
El objetivo del presente artículo es rastrear y examinar el planteamiento acerca del desarrollo de la personalidad en un extracto de los diarios tempranos de Kierkegaard conocido de forma convencional como el "diario de Gilleleje". En el verano de 1835, Søren Kierkegaard, quien en aquel momento tenía veintidós años y estaba todavía inscrito como estudiante en la Universidad de Copenhague, viajó a Gilleleje en la parte más septentrional de la isla de Selandia. En el diario de estas vacaciones, el escritor registró observaciones de todo tipo: descripciones de paisajes, relaciones de encuentros con algunas de las personalidades de la zona, imágenes coloridas del estilo de vida provincial, alusiones a leyendas populares, relatos históricos de la región, etcétera. Se trata, en pocas palabras, de un diario de viaje.

El documento, sin embargo, también incluye las reflexiones de un joven Kierkegaard sobre la cuestión íntima y existencial del descubrimiento del propio Yo y la construcción de la personalidad. Como se sabe, uno de los temas fundamentales en la obra del escritor danés es precisamente el desarrollo de la conciencia y la personalidad del individuo humano a través de su vida o, dicho en términos existencialistas modernos, la transición de una existencia inauténtica a una existencia auténtica. En varias de las obras principales de Kierkegaard se encuentra este leitmotiv. En O lo uno o lo otro de 1843, por ejemplo, el seudónimo Juez Wilhelm exhorta a su amigo, el también seudónimo esteta, a desesperar y elegirse a sí mismo con el fin de encontrar el camino hacia una vida plena. Un consejo parecido lo encontramos en dos obras posteriores, El concepto de la angustia de 1844 y La enfermedad mortal de 1849, en las que se establecen de forma respectiva las categorías de la angustia y la desesperación como condiciones necesarias para el crecimiento existencial. El mismo tema es central, como resulta evidente por el título, en Etapas en el camino de la vida de 1845. Con esto en mente, me gustaría destacar la importancia filosófica del diario de Gilleleje, pues si bien este escrito no cuenta con el mismo rigor intelectual de la obra madura, es posible descubrir aquí el planteamiento germinal e incluso paradigmático de esta cuestión fundamental.

El diario de Gilleleje nos deja ver que el análisis de Kierkegaard parte de ciertas premisas. Descubrimos, en primer lugar, la insistencia en una cosmovisión en la que el mundo no es un sitio caótico y carente de sentido, como sugerían algunos de los intelectuales románticos y nihilistas de la época, sino un todo ordenado y orgánico. La pregunta por el desarrollo de la personalidad está inserta en tal cosmovisión. Se trata, pues, de encontrar el puesto determinado del Yo dentro del todo orgánico que 
es el mundo. Kierkegaard se referirá en varias ocasiones a esto como la "búsqueda del punto arquimédico". De aquí se derivan distintas preguntas más específicas en torno al despertar de la conciencia, la comprensión del "destino" o providencia, e incluso la elección de una profesión mundana. Hacia el final del diario, Kierkegaard expone por primera vez uno de los conceptos clave de su pensamiento: la verdad subjetiva. Esta parece ser la respuesta provisional del joven escritor a su cuestionamiento sobre el desarrollo de la personalidad: el cimiento para la plenitud existencial es el descubrimiento de una verdad que sea verdad para mí, una idea por la cual, en palabras de Kierkegaard, el individuo esté dispuesto a vivir y morir.

En la primera sección del artículo, Anotaciones sobre el carácter del diario de Gilleleje, examino el documento que es la base del estudio. Además de describir las características del diario de Gilleleje, se discute de forma breve su historicidad y su naturaleza literaria. En la segunda sección, Goethe y la invención de la novela danesa en los años veinte y treinta, analizo el contexto literario en el que surge el diario de Gilleleje. El fenómeno cultural clave de este periodo es el culto literario en torno a la figura de Goethe, la adopción de su cosmovisión en la escena intelectual danesa y la creación de un nuevo género literario, la novela corta. Me gustaría sugerir que es posible entender el diario de Gilleleje como un intento de Kierkegaard por elaborar su propia novela corta. El objetivo de la tercera sección, titulada Orgullo y bumildad. La experiencia de Gilbjerget, es ofrecer una interpretación filosófica de la presunta visión de Kierkegaard en Gilbjerget. De forma ficticia o real, Kierkegaard dibuja una escena en la que él, el observador, constata la totalidad que es el mundo al contemplar la inmensidad del mar. Esto lo conduce a reflexionar sobre el papel del individuo dentro del todo. Se concluye que el sujeto debe encontrar un equilibrio entre la autoafirmación arbitraria y la disolución de la individualidad. En la cuarta sección, El destino en la formación de la personalidad. La carta a Lund, se analiza la presunta carta incluida al final del diario de Gilleleje. En este documento, Kierkegaard prosigue con su búsqueda del "punto arquimédico", el equilibrio en la relación entre el individuo con la totalidad. Por último, en la quinta y última sección analizo el concepto de verdad subjetiva. En este momento culminante, Kierkegaard sugiere que el punto arquimédico, ese "destino" [Bestemmelse] que le corresponde a cada individuo dentro del todo que es el mundo, tiene la forma de una verdad subjetiva, esto es, la de una idea que es apropiada de modo existencial por el sujeto. Se concluye, pues, que el desarrollo de la personalidad - que para Kierkegaard no es otra cosa que el camino que recorre el individuo para encontrar su sitio en el mundo- culmina con el descu- 
brimiento de esta verdad subjetiva. Se trata de una primera intuición que el escritor danés seguirá desarrollando a lo largo de su obra.

\section{ANOTACIONES SOBRE EL CARÁCTER DEL DIARIO DE GILLELEJE}

Entre 1835 y 1840, Søren Kierkegaard escribió sus diarios en diez cuadernos rotulados con las letras AA, BB, CC, etcétera. El denominado diario de Gilleleje, incluyendo la presunta carta a Peter Wilhelm Lund con su extensa "posdata", aparece en las primeras doce entradas del cuaderno AA (Kierkegaard, 2011: 60-87; 2000: 7-30) ${ }^{1}$. Con respecto a la cronología, el único material que está fechado es la entrada $7^{2}$ (Kierkegaard, 2011: 67; 2000: 16) y la carta a Lund $^{3}$ (Kierkegaard, 2011: 73-79; 2000: 18. 23). Aun así, dentro del texto encontramos las fechas de las distintas etapas del viaje. En un sentido exclusivamente histórico, la mayoría de los comentadores está de acuerdo en que Kierkegaard estuvo en Gilleleje entre el 17 de junio y el 24 de agosto de 1835, hospedándose en la posada de Kristoffer Mentz. Todo indica que el motivo del viaje había sido el estado de depresión de Kierkegaard. Preocupados por su salud, su hermano mayor y su padre le aconsejaron que pasara una temporada fuera de Copenhague.

El texto mismo, en cambio, ofrece algunos problemas de interpretación y ha sido el objeto de discusiones que incluso hoy en día no han terminado por resolverse. El primer compilador de los papeles póstumos de Kierkegaard [Efterladte Papire], Hans Peter Barfod (1869), así como los editores de los Papirer, Peter Andreas Heiberg y Viktor Kuhr (1909), no dudan en dar por supuesto algo que, hemos de admitir, parecería obvio: que el diario de Gilleleje fue creado durante el viaje de Gilleleje, es decir, en el verano de 1835. Más tarde, Henning Fenger, discípulo de Viktor Kuhr, señaló que no era necesario que esto fuera así. Principalmente a partir del análisis filológico de los libros citados por Kierkegaard en este diario de viaje y de la comparación de algunos pasajes con otros textos posteriores de los diarios, Fenger (1980: 89-115) quiso demostrar que este escrito había sido concebido, de hecho, un año después.

1 Para conveniencia del lector, al citar el diario de Gilleleje se ofrece en primer lugar la referencia a la traducción al castellano de María Binetti (2011) y luego, para quien desee acudir a la fuente original, se incluye enseguida la referencia a la última edición danesa de las obras de Kierkegaard (2000). En el caso de las citas textuales, tomo en consideración la traducción de Binetti, aunque he hecho algunas variaciones basándome en la edición danesa.

2 En el encabezado de la entrada leemos: "Hillerod f. 25 de julio de 1835".

3 La carta está fechada el 1 de junio de 1835 en Copenhague. La posdata está fechada el 1 de agosto de 1835 en Gilleleje. 
Una polémica más específica fue la que suscitó la carta o borrador de carta a Peter Wilhelm Lund, el hermano del cuñado de Kierkegaard. Una vez más se dio por supuesto algo que parecía evidente y una vez más Fenger lo puso en duda. Niels Thulstrup (1953), editor de las cartas y documentos del escritor danés, no titubeó en colocar este documento entre las cartas reales de Kierkegaard y, todavía más, no tuvo ningún problema en asegurar que la carta estaba dirigida a Lund. Fenger, por su parte, destacó que las únicas evidencias que Thulstrup tenía a la mano eran, por un lado, la forma epistolar del documento y, por otro, la mención de que el destinatario de la supuesta epístola radicaba en Brasil. Lund, paleontólogo de profesión, residía en efecto en Lagoa Santa en el Imperio del Brasil, pero su nombre no se menciona de forma explícita en ninguna parte del documento. El argumento fuerte de Fenger (1980) consiste en sugerir que la carta en realidad formaba parte de un proyecto de Kierkegaard para crear una novela epistolar, un género literario que estaba de moda por aquel entonces (89-96). En términos generales, Fenger propone que el diario de Gilleleje debe leerse más como un proyecto literario al estilo de la Bildungsroman que como un documento histórico, una tesis a la cual se ha sumado más recientemente - si bien con ciertas reservas- el importante comentador y biógrafo de Kierkegaard, Joakim Garff (2003: 355-369).

En la última edición de los escritos de Kierkegaard, Soren Kierkegaards Skrifter, los editores, entre ellos Garff, se han mostrado más cautelosos con relación al tema del diario de Gilleleje y han adoptado una postura hasta cierto punto conciliadora. Aunque en general permanecen en la posición más razonable según la cual el diario de Gilleleje fue creado probablemente durante aquel verano de 1835, también reconocen que no es imposible que algunos pasajes fueran redactados y añadidos más tarde (Brunn \& Knudsen, 2000).

El problema sobre la ubicación cronológica del diario de Gilleleje es de una importancia secundaria para este trabajo. Sí es relevante, por otro lado, el carácter literario y no meramente histórico que tanto Fenger como Garff le atribuyen al texto. Es particularmente interesante su relación con la tradición de la Bildungsroman alemana. Algunas de las primeras intuiciones y conceptos de Kierkegaard en torno a la cuestión de la visión de vida, el desarrollo de la personalidad y la verdad subjetiva se nutren de dicha tradición y del contexto literario en el que fueron concebidas. En el siguiente apartado, examinaré la influencia que el ámbito literario ejerció sobre este escrito temprano de Kierkegaard. 
2. GOETHE Y LA INVENCIÓN DE LA NOVELA DANESA EN LOS AÑOS VEINTE Y TREINTA

Está bien documentado que el poeta Johan Ludvig Heiberg fue el responsable de introducir el pensamiento de Hegel en la escena académica de Copenhague a principios del siglo XIX. En el verano de 1824, Heiberg (1862: 500) entró en contacto con la filosofía hegeliana y, de acuerdo con su propio testimonio en sus "Fragmentos autobiográficos", experimentó una especie de epifanía. A partir de ese momento, el poeta se convirtió al hegelianismo y, al regresar a Copenhague un año después, dedicó todos sus esfuerzos a difundir la filosofía del pensador alemán en Dinamarca a través de ensayos filosóficos y, de forma principal, obras de teatro.

Sin embargo, también era un admirador ferviente de Goethe, a quien consideraba como el único escritor capaz de rivalizar con Hegel. No se menciona con tanta frecuencia el papel que desempeñó Heiberg como promotor y casi panegirista de Goethe en la capital danesa. El "furor", como lo llama Henning Fenger (1980: 81-88), comenzó poco después de la muerte del gran poeta alemán. El 19 de junio de 1832, algunos meses después del fallecimiento de Goethe, se representó en el Teatro Real de Copenhague un fragmento del Fausto traducido por Heiberg y Henrik Hertz. El 2 de mayo de 1834 se representó también Egmont, con todo y la obertura compuesta por Beethoven, y de ahí en adelante sería una pieza recurrente en el repertorio del Teatro Real. Clavijo, una de las obras favoritas de Kierkegaard, tuvo una suerte parecida. Desde luego, la mano de Heiberg estuvo detrás de la introducción y promoción de Goethe en la escena danesa (Nun \& Stewart, 2008: 51-87). En 1829, Heiberg había recibido el nombramiento como poeta y traductor oficial del teatro; desde este importante puesto, hizo todo lo posible por abrir espacios para representar la obra del poeta de Fráncfort.

Pero su apreciación por Goethe no era solo artística, sino también filosófica. El arte y la filosofía estaban estrechamente ligados en el pensamiento de Heiberg. Este solía utilizar el pensamiento de Hegel para darle un sustento teórico a sus dramas. De manera parecida, intentó incorporar en su obra el pensamiento goethiano. Uno de sus primeros trabajos acerca de Goethe fue un análisis del intercambio epistolar entre este y Schiller. Heiberg (1861) expuso su comentario junto con algunas traducciones suyas del intercambio en una larga serie de artículos publicados en el Kjobenhavns flyvende Post, un diario editado por él mismo. A partir de este momento, Heiberg intentará asociar el nombre de Goethe con el de Hegel y, de hecho, lo hará de forma explícita en su obra de 1833, Sobre la importancia de la filosofía para la época presente [Om Philosophiens Betydning for 
den Nuvarende Tid]. La descripción que ahí hace de los dos pensadores alemanes deja en claro el entusiasmo de Heiberg. Por su importancia, me ha parecido necesario reproducir el pasaje completo:

Goethe y Hegel son, sin duda alguna, los dos hombres más grandes que la época moderna ha producido. Nadie más merece ser llamado, en la misma medida que ellos, representante de nuestra época, ya que sus obras contienen toda la vida del espíritu de nuestra época como algo que existe y está presente, es decir, como algo que abarca la unidad del futuro con el pasado. Aunque ambos han sido arrebatados de su vida terrena, y esto casi de forma simultánea, algo que, en ese sentido, completaría el paralelo entre los dos, si bien pareció que uno siguió el mandato de la ley natural, mientras que el otro fue arrebatado quizás en el punto culminante de su obra, aun así están los dos lejos de pertenecer al pasado y a los muertos. Por el contrario, ellos, que de todos los espíritus son los que están más presentes, únicamente serán comprendidos por las generaciones futuras. Con respecto a Hegel, la mayoría de la gente admite de forma abierta que no lo entiende; pero el hecho de que Goethe en el fondo no es mejor comprendido se demuestra por el hecho de que la poesía - para gozo tanto del poeta como del público- se mueve en una multitud de direcciones inferiores, las cuales, desde la perspectiva de la poesía de Goethe, son algo ya pasado y superado por su propia poesía, al igual que la Idea se eleva por encima de todas las etapas inferiores y finitas de desarrollo. El motivo por el que nuestro culto mundo literario encuentra placer en Goethe a pesar de que no lo entiende reside precisamente en el hecho de que él era un poeta, pues la poesía no muestra la verdad en la forma que le es propia, sino más bien en una contingente, de suerte que uno puede relacionarse con ella y, así, comprender de manera exotérica aquello que solo el observador esotérico puede ver bajo la luz correcta. Pero, en este sentido, no hay ningún motivo para colocar a Goethe por encima de los otros poetas. Por lo tanto, cuando se escucha semejante afirmación entusiasta, uno puede estar bastante seguro de que eso difícilmente se dice en serio y se trata más bien de un mero eco del juicio de un corifeo crítico. (Heiberg, 1833: 36-37)

Desde luego, la exaltación de Heiberg no es un "mero eco". Él, “observador esotérico", sí comprende a Goethe. De forma análoga a Hegel, quien expone - según Heiberg- una verdad total a partir de la exposición de la evolución dialéctica de realidades finitas, también Goethe consigue comprender y exponer la verdad infinita mediante la representación poética de caracteres y situaciones concretas (Nun \& Stewart, 2008: 56). Pero a diferencia de Hegel, quien resulta totalmente incomprensible para el gran público, Goethe vuelve accesible esta verdad gracias a la naturaleza atractiva de su poesía. De hecho, este era el punto medular de la propuesta estética y poética de Heiberg: revelarle al gran público verdades 
universales a través del arte, en específico a través del vodevil (el cual había introducido en Dinamarca después de su estancia en París) y, más tarde, mediante la denominada (por él mismo) poesía especulativa.

Heiberg seguiría escribiendo acerca de Goethe en los años siguientes, aunque su atención se concentraría cada vez más en el tema concreto de Fausto. La influencia de la obra de Goethe es fundamental para comprender la literatura danesa de esta época. La cosmovisión poética goethiana impulsó de forma decisiva la difusión de un nuevo género literario en Dinamarca: la prosa literaria y, de modo más específico, la novela corta ${ }^{4}$.

La especialidad literaria de Heiberg era el drama cómico, especialmente el vodevil. Es comprensible, en consecuencia, que su atención se dirigiera principalmente al aspecto dramático de la obra de Goethe. Sin embargo, Heiberg no era el único miembro del "culto goethiano" en Dinamarca. Por ejemplo, uno de los pocos puntos en común que lo unía con su némesis literario, el poeta romántico Adam Oehlenschläger, era precisamente la afición por la obra de Goethe. Oehlenschläger conoció de forma personal a Goethe en 1806 y si bien la influencia más notable del poeta alemán puede observarse mejor en la composición de versos del danés, eso no fue impedimento para que este escribiera también una novela corta en 1825 con un distintivo sello goethiano: La isla en los mares de sur [Øen i Sydhavet].

Otro caso de un escritor fuera del círculo heibergiano que desarrolló de forma fructífera la prosa es el de Steen Stinsen Blicher, el autor danés que logró tal vez los mejores resultados con la novela corta en el siglo XIX. Aunque suele convenirse en que la principal influencia de Blicher era Walter Scott y no Goethe, el espíritu de su principal novela corta, Diario de un párroco de provincia [En Landsbydegns Dagbog], expone básicamente el mismo mithos que el Wilhelm Meister goethiano, es decir, es la historia de un joven que intenta encontrar su camino por la vida. Vale la pena señalar que Kierkegaard era un admirador ferviente de la obra de Blicher. Hay que mencionar también el nombre del escritor que llevó la prosa danesa al escenario internacional, Hans Christian Andersen, cuyas novelas cortas al estilo de Wilhelm Meister (también en el sentido de que son claramente autobiográficas), El improvisador [Improvisatoren], O. T. y Solo un músico [Kun en Spillemand], gozaron de gran prestigio en su momento.

\footnotetext{
$4 \quad$ En castellano solemos referirnos a la novela corta, esa especie de punto intermedio entre el cuento y la novela convencional, con el mismo nombre genérico de novela. En danés, en cambio, existen los dos términos, ambos tomados del francés, para nombrar estos géneros: Novelle para la novela corta y Roman para la novela.
} 
Dentro del grupo más cercano a Heiberg (y a Kierkegaard), podemos apuntar a Poul Martin Møller, Frederik Christian Sibbern y Thomasine Gyllembourg. Møller, quien era amigo, profesor y mentor de Kierkegaard, se dio a conocer en la escena literaria con una novela corta inconclusa titulada La aventura de un estudiante danés [En dansk Students Eventyr]. Aunque Møller era bien recibido en casa de los Heiberg, que era a la sazón el principal punto literario en Copenhague, su espíritu libre y romántico era poco afín al formalismo rígido de la escuela heibergiana. La historia de un estudiante universitario que viaja por el mundo para encontrarse a sí mismo era el tipo de relato con el que Kierkegaard podía identificarse. Sibbern, quien también era amigo y profesor de Kierkegaard, tenía una formación eminentemente filosófica y el lenguaje que empleaba en sus obras teóricas resultaba a menudo oscuro y confuso. A pesar de esto, de su pluma surgiría uno de los clásicos de la literatura danesa, las Cartas póstumas de Gabrielis [Efterladte Breve af Gabrielis] de 1826, una novela epistolar amorosa inspirada sin duda en el Werther de Goethe y concebida para aplacar la pasión que Sibbern sentía por la hermana de Oehlenschläger, Sophie. Por último, Thomasine Gyllembourg, la madre de Heiberg, comenzó su carrera literaria con la novela corta La familia Polonius [Familien Polonius] de 1827. Sin embargo, alcanzaría la fama años después con el clásico Una historia cotidiana [En Hverdagshistorie]. La novela causó tal sensación que a partir de ese momento Gyllembourg firmó sus posteriores relatos con el seudónimo "El autor de Una historia cotidiana". Se sabe que Kierkegaard consideraba los relatos de Fru Gyllembourg como el paradigma de lo que una novela debía ser.

De esta manera, los años veinte y treinta fueron el escenario del boom de la novela corta danesa. Kierkegaard, por supuesto, estaba al tanto de esta vanguardia literaria. Conocía de forma personal a varios de los autores y era lector asiduo de la mayoría. En cuanto a su gusto literario, seguía la moda impuesta por Heiberg. En aquella época, Kierkegaard se consideraba a sí mismo como un discípulo fiel de la escuela heibergiana y hacía todo lo posible por lograr la aceptación del poeta. Esto se reflejaba también en su entusiasmo por la obra de Goethe. Observemos, por ejemplo, el comentario que hace acerca del Wilhelm Meister en una entrada de 1836, donde destaca las mismas virtudes que Heiberg había descubierto en los escritos del poeta alemán:

Si tuviera que señalar en pocas palabras aquello que realmente considero magistral en el Wilhelm Meister de Goethe, diría que es la providencia integral [afrundede Styrelse] que predomina en el todo [det Hele], el completo orden del mundo [Verdensorden] moral fichteano que se desarrolla doctrinalmente en la novela misma, el cual es inmanente al todo [ $i$ det Hele] y que 
conduce de forma gradual a Wilhelm hacia el punto, si se me permite ponerlo así, postulado teóricamente, de modo que, al final de la novela, la visión de mundo [Verdens Anskuelse] que el poeta ha propuesto y que anteriormente existía fuera de Wilhelm, ahora vive y se encarna en él, y esto explica la más perfecta impresión de totalidad [det fuldendte Totalindtryk] que esta novela expresa quizá más que cualquier otra; se trata en verdad del mundo entero [den hele Verden] representado en un espejo, un genuino microcosmos. (Kierkegaard, 2000: 102)

Es evidente el énfasis que Kierkegaard coloca en las categorías del todo [det hele] y el orden total que impera sobre este ("providencia integral", "un genuino microcosmos"), todo lo cual se manifiesta de forma "magistral" en el personaje concreto de Wilhelm. Es un buen resumen del proyecto estético de Heiberg visto a través de la novela de Goethe.

Kierkegaard, lector ávido y comprador compulsivo de libros, no tardó en adquirir una copia de las obras completas de Goethe. Por una entrada de su diario de 1835 sabemos que había leído con cuidado las Cartas de Gabrielis de Sibbern en marzo de ese año (Kierkegaard, 2000: 95), unos meses antes del viaje a Gilleleje. También en marzo de 1835 un amigo cercano de Kierkegaard, P. E. Lind, publicaría una novela corta, Johan Gordon, que sería aclamada por la crítica. Tal vez era el momento indicado para que el propio Kierkegaard probara suerte con su propia nouvelle.

No podemos asegurar si el diario de Gilleleje es, como asegura Henning Fenger y sugiere Joakim Garff, un esbozo de novela corta al estilo del Wilhelm Meister. Pero si examinamos con cuidado su contenido, parece que en este diario es posible descubrir ese principio que tanto Kierkegaard como Heiberg aplaudían en la obra goethiana, a saber, la revelación de una visión integral de mundo a través de la subjetividad concreta de un personaje.

\section{ORGULLO Y HUMILDAD. LA EXPERIENCIA DE GILBJERGET}

El 29 de julio, Kierkegaard salió de la posada "Gilleleje" y se dirigió hacia el oeste. Cruzó el llamado puente negro y recorrió la línea costera hasta llegar al punto más septentrional de la isla. Ahí el camino se interrumpe de forma abrupta y le da paso a un vasto acantilado que le ofrece al caminante una vista sin obstáculos del mar de Kattegat. Gilbjerget - Gilberghoved en la actualidad- es el nombre del acantilado. Hoy en día el viajero que camina hasta este punto se encuentra con una gran roca que le recuerda con vehemencia que Kierkegaard estuvo en ese mismo lugar, contemplando ese mismo paisaje. El monolito tiene grabado el 
nombre del escritor y la siguiente inscripción: Hvad er sandhed andet end at leve for en ide?, "¿Qué es la verdad sino vivir por una idea?"

La reflexión que Kierkegaard desarrolla en este pasaje tiene como ocasión una experiencia que, tal como se describe, parecería sobrenatural. En las primeras líneas se lee lo siguiente:

Cuando entonces estaba aquí [Gilbjerget] en una noche tranquila, mientras el mar entonaba su canto con profunda pero tranquila seriedad, cuando mis ojos no encontraban siquiera un navegante sobre la inmensa superficie, sino solo el mar que lindaba con el cielo y el cielo con el mar. Cuando además se acallaban las ajetreadas ocupaciones de la vida y los pájaros cantaban sus nocturnos, entonces a menudo se levantaban de sus tumbas mis pocos y queridos muertos o, mejor dicho, me imaginaba que no estaban muertos. Me sentía muy bien en medio de ellos, descansaba en su abrazo y era como estar fuera de mi cuerpo, flotando con ellos en un éter superior, hasta que el ronco grito de una gaviota me recordaba que estaba solo y todo se esfumaba de mi vista y volvía con el corazón melancólico a mezclarme con las multitudes, sin olvidar esos sagrados momentos. (Kierkegaard, 2011: 68-69; 2000: 13-14)

Salta a la vista que Kierkegaard recurre a imágenes literarias para explicar la reflexión con la que cierra la entrada. La mención de sus "pocos y queridos difuntos" es una clara referencia autobiográfica, una alusión a sus hermanos fallecidos. Pero el elemento predominante del pasaje es el encuentro del observador, Kierkegaard, con una extensión natural ilimitada representada por un mar en el que no hay navegantes y un cielo igualmente vasto. Frente "al poder del mar y la lucha de los elementos" (Kierkegaard, 2011: 69; 2000: 14), el observador recuerda su nulidad y, al mismo tiempo, "se afirma como señor de la naturaleza" (2011: 71; 2000: 15). La forma y las imágenes empleadas por el escritor danés son un eco del sentimiento de lo sublime, un lugar común todavía entre los poetas de la época.

Sin embargo, a través de esta descripción Kierkegaard plantea una serie de intuiciones que es importante tomar en cuenta.

(a) En primer lugar, gracias a este contacto con la naturaleza el observador obtiene una visión de la totalidad: "Cuando el todo [det Hele] mostraba sus contornos más amplios, más fuertes, y yo no me perdía en el momento, como suele ocurrir, sino que veía el todo en su totalidad [det Hele $i$ sin Totalitet], entonces me fortalecía para tomar las cosas de otro modo, para reconocer cuántas veces he cometido errores y perdonar así a los demás" (Kierkegaard, 2011: 69; 2000: 14). Al igual que en la entrada 
acerca del Wilhelm Meister, aquí también aparece la premisa de que existe una totalidad que puede ser aprehendida.

(b) En segundo lugar, la comprensión de que cada elemento particular tiene un carácter necesario cuando es visto dentro de esta totalidad. Kierkegaard ilustra lo anterior con una referencia evangélica: "ni un solo gorrión cae a tierra sin la voluntad de vuestro Padre celestial" (Mateo 10:29).

(c) En tercer lugar, el esclarecimiento de cuál es el papel que el propio observador desempeña dentro de la totalidad. Frente a la visión total, el observador se percata de que no es "como un enclítico de que esos que a menudo me rodean", aunque tampoco es el "principio constitutivo de un pequeño círculo" (Kierkegaard, 2011: 69; 2000: 14). En otras palabras, no tiene un carácter meramente relativo (como las partículas enclíticas), pero tampoco puede convertirse en el centro aislado de un microcosmos creado por él mismo. Lo primero representaría un nivel de conciencia inferior. Lo segundo, desde mi punto de visa, se asemeja a la postura de los poetas del Romanticismo, a saber, sería una posición de aislamiento subjetivo en la que el individuo se transforma en el principio constitutivo de su propio mundo. Lo que Kierkegaard (2011: 69; 2000: 14) busca es una síntesis entre estas dos perspectivas, un matrimonio entre "orgullo y humildad" que represente la conciencia de la naturaleza simultáneamente contingente (en cuanto particular) y necesaria (como parte de un organismo total) del individuo. En este pasaje, Kierkegaard (2011: 70; 2000: 15) compara dicha posición con "ese punto arquimédico desde el cual podría levantar al mundo entero, ese punto que, justo por eso, tiene que estar fuera de este mundo, fuera de los límites del tiempo y el espacio".

(d) En cuarto lugar, el modo en que se alcanza el mencionado punto arquimédico. En la cita anterior, Kierkegaard señala que este punto reside "fuera de los límites del tiempo y el espacio". Esto puede significar que, a fin de obtener esta visión superior, es preciso ir más allá de una perspectiva puramente finita, es decir, es necesario adoptar, de acuerdo con la terminología del hegeliano Heiberg, una postura especulativa. Aquí encontramos otra figura evangélica: "Para aprender la verdadera humildad - y con esta expresión me refiero al mencionado estado de ánimoes bueno que el hombre se sustraiga al alboroto mundano (Cristo también se retira antes de avanzar por su camino espinoso mientras el pueblo quiere proclamarlo rey), ya que en la vida tanto lo que deprime como lo que eleva son elementos demasiado intensos para hacer posible el equilibrio verdadero" (Kierkegaard, 2011: 70; 2000: 15).

(e) En términos literarios, lo anterior podría relacionarse con el tema tradicional de la Bildungsroman en el cual el protagonista debe abandonar 
su ciudad natal y viajar por tierras lejanas para alcanzar una nueva perspectiva. Esto lo vemos en el caso del Wilhelm Meister, por supuesto, pero también en composiciones locales como las Cartas de Gabrielis de Sibbern y La aventura de un estudiante danés de Møller. También es el caso del propio Kierkegaard, quien parte de Copenhague y viaja a Gilleleje.

La experiencia real o literaria de Gilbjerget establece una base teórica (la dialéctica contingencia-necesidad dentro del marco de una totalidad) a partir de la cual, en mi opinión, pueden comprenderse mejor las reflexiones con las que concluye el diario de Gilleleje. En los siguientes dos apartados analizaré el último segmento del diario, la carta a Lund y su posdata, que es donde se desarrollan estas reflexiones.

4. EL DESTINO EN LA FORMACIÓN DE LA PERSONALIDAD. LA CARTA A LUND

Se ha señalado antes que los comentadores no han logrado responder de modo conclusivo a la cuestión sobre la autenticidad histórica de este documento. $\mathrm{Al}$ igual que en el caso de Gilbjerget, no nos corresponde profundizar en ese asunto. Para nuestros fines, resulta lo mismo si es un escrito histórico o parte de una novela epistolar. Pero con independencia de esto, creo que es relevante observar la fecha que está apuntada al comienzo de la carta: 1 de junio de 1835. De forma histórica o ficticia, Kierkegaard deja en claro que los pensamientos expuestos en la "carta" corresponden al periodo inmediatamente anterior a Gilleleje. En efecto, el viaje comenzó el 17 de junio, un par de semanas después. El mensaje, creo, no es fortuito. Kierkegaard situó de forma intencional la carta al final del diario, como si quisiera decirle al lector: "Esto es lo que pensaba antes de ir a Gilleleje". Si el diario fuera de hecho un intento de novela, la estrategia tendría mucho sentido: el protagonista sale de su hogar con una serie de convicciones que solo ahora comienza a poner en duda, pero entonces, gracias a su experiencia en el exterior, consigue por último abrir los ojos. Entonces se nos muestra un contraste final entre la visión anterior y la posterior. Pero incluso si se trata de un documento histórico, parece que el autor desea marcar un antes y un después.

El destinatario de la carta, se presume que Peter Wilhelm Lund, es un paleontólogo que reside en Brasil. El remitente, Kierkegaard, intenta explicarle las dificultades a las que se ha enfrentado en su joven existencia estudiantil. La exposición puede dividirse en dos partes. En la primera, Kierkegaard describe el desarrollo vital de lo que podríamos llamar la primera juventud desde un estado inconsciente y pasivo hasta el despertar de la subjetividad. En la segunda cambia el enfoque del argumento. 
Mientras que antes se ofrecía una explicación universal y abstracta, en la segunda parte Kierkegaard hace referencia a su experiencia personal. El punto central es el problema de cómo encontrar una vocación adecuada. El "narrador" desarrolla esta cuestión aludiendo a su propia relación con las ciencias naturales y la teología.

(a) La primera imagen que se nos presenta es la del destinatario, el paleontólogo, como la representación de un hombre que ha sabido encontrar su sitio en la vida. Tenemos, por el otro lado, al joven que "todavía sueña con su destino [Bestemmelse]" (Kierkegaard, 2011: 73; 2000: 18). Creo que no es casual la elección del término Bestemmelse. Esta palabra, empleada con frecuencia en el diario de Gilleleje, posee distintas acepciones y es posible traducirla, según el contexto, como "destino" o "determinación", aunque también puede adoptar el sentido más técnico de "disposición" o incluso el de "categoría". En cualquiera de estos casos, parece que el uso recurrente del término responde a la visión de un mundo orgánico en el que cada una de las partes desempeña un único papel concreto. Así, la noción de "destino" encaja de forma excepcional en el esquema expuesto en el episodio de Gilbjerget. Aquí el planteamiento es más complejo. Se parte de la premisa de que el ser humano debe averiguar cuál es su destino y es responsable de actualizarlo, por decirlo de alguna manera. Pero esto no es posible todavía en la primera juventud, cuando la conciencia todavía no despierta y, en consecuencia, el individuo adopta una posición pasiva:

Nuestra primera juventud es como la flor del amanecer que tiene sobre su cáliz una deliciosa gota de rocío, en la que el entorno se refleja de forma armónica y melancólica. Pero el sol pronto se eleva sobre el horizonte y la gota de rocío se seca. Con ella se esfuman los sueños de la vida y entonces solo cuenta lo que el hombre pueda hacer por alcanzar una nueva imagen de las flores, capaz de producir - por sus propias fuerzas, como la adelfauna gota que permanezca como el fruto de su vida. (Kierkegaard, 2011: 73; 2000: 18)

En esta primera etapa, el carácter del individuo es un reflejo de su entorno. Cuando el sol se eleva, es decir, cuando la conciencia despierta, el rocío se seca (el carácter dependiente y pasivo) y el individuo debe, para continuar con la metáfora, procurarse su propio alimento como la adelfa, tiene que hacerse cargo de sí mismo. Es importante destacar que este "hacerse cargo de sí mismo" no equivale a una construcción arbitraria y caprichosa de la personalidad. De acuerdo con la visión que Kierkegaard ha adoptado como base hasta ahora, partimos del supuesto de que 
existe una totalidad orgánica dentro de la cual cada parte ocupa un sitio específico. De esta manera, no se trata tanto de asumir una libertad sin límites que podría conducir a cualquier parte, sino de "situarse en el lugar que a uno le es propio, aunque este no siempre es fácil de encontrar" (Kierkegaard, 2011: 73; 2000: 18).

Aquí es donde reside la dificultad principal y Kierkegaard se esfuerza sin éxito por encontrar una solución adecuada. Se admite que existen "naturalezas afortunadas" que, en virtud de una especie de intuición, son capaces de conocer desde el comienzo cuál es el camino que deben seguir. Poseen en su interior un "imperativo categórico" que les indica en cada momento cuál es el curso correcto (Kierkegaard, 2011: 73; 2000: 18-19). Pero como una intuición de esta clase no explica mucho, es necesario continuar indagando. Los demás seres humanos, la inmensa mayoría, pasan a un estado de fermentación en el que son víctimas de la duda. Entre estos, hay algunos que sucumben y sencillamente se dejan gobernar por su entorno (Kierkegaard, 2011: 73; 2000: 19). Hay otros, en cambio, que se sumergen cada vez más en el territorio de la duda. Se le da a entender al lector que el autor/Kierkegaard pertenece a este grupo. Como señala Fernanda Rojas refiriéndose al fenómeno psicológico de la angustia, "el mirar del hombre hacia el abismo, que es la posibilidad, hace que se agarre de su finitud porque teme caer, pero a la vez el abismo lo llama y lo invita a saltar" (2016: 145). En este punto, encontramos una de las primeras exposiciones acerca de la figura de Fausto y el denominado problema fáustico, es decir, la cuestión sobre la duda y la desesperación. El famoso nigromante alemán, como se sabe, será uno de los temas favoritos de Kierkegaard. En este pasaje de la carta, no obstante, solo se alude al episodio en el que Fausto le entrega el alma al demonio a cambio de una sabiduría terrena ilimitada. Mefistófeles le revela a Fausto "el interior de los hombres y los secretos ocultos de la tierra" (Kierkegaard, 2011: 74; 2000: 19), pero no consigue iluminarlo con respecto a lo que es en verdad esencial. Con esto, Kierkegaard parece sugerir que el "destino" que le es propio a cada individuo (o el "punto arquimédico" según el episodio de Gilbjerget) no puede comprenderse a través de la adquisición de conocimientos científicos o, en un sentido más general, de una sabiduría mundana. Kierkegaard volverá a esta cuestión en la posdata de la carta.

(b) Después de plantear de forma universal el tema de la duda como un problema aplicable a todo el género humano (Fausto es, desde su punto de vista, una figura universal), en la segunda parte de la carta el autor decide abordar dicha cuestión desde una perspectiva más específica y apelando a su experiencia personal: 
Esta duda puede manifestarse también en otra esfera. Incluso para el hombre que ha logrado aclarar ciertos puntos centrales de sí mismo, aparecen en la vida otras preguntas también importantes. Todo hombre desea de forma natural actuar en el mundo conforme a sus capacidades, y por eso desea formar sus capacidades en un sentido determinado, es decir, en el sentido más apropiado a su individualidad. Pero ¿cuál es ese sentido? Aquí se me presenta un gran problema. Parezco Hércules, solo que no estoy en una encrucijada; no, aquí se abren muchos más caminos y es mucho más difícil elegir el correcto. Quizá sea una desgracia para mí interesarme en demasiadas cosas y no decidirme por ninguna. (Kierkegaard, 2011: 74-75; 2000: 19-20)

La anterior parece una alternativa sensata: el destino o determinación de cada uno debe estar en conformidad con las aptitudes individuales. En tal caso, la solución consistiría simplemente en averiguar cuáles son dichas aptitudes. Pero la dificultad es que el autor — de quien, según parece, hemos de suponer que posee muchas habilidades- se interesa por demasiadas cosas. No solo se trata de elegir, como Hércules en su encrucijada, entre la virtud y la voluptuosidad. Kierkegaard, el hombre moderno, se enfrenta a un repertorio enorme de posibilidades. No obstante, el autor reduce sus intereses a dos campos: las ciencias naturales y la teología. En la exposición de la relación entre el autor y estas dos disciplinas, encontramos una vez más el tema hasta ahora más recurrente en el diario de Gilleleje, a saber, la importancia de obtener una visión de conjunto y las desventajas de limitarse a un conocimiento de particularidades.

Con relación a la ciencia, nos enteramos de que el autor no se siente atraído por los científicos que "conocen una gran cantidad de particularidades [en stor Mangde af Enkeltheder], pero no mucho más, solo han puesto las bases para el pensamiento y la elaboración de otros" (Kierkegaard, 2011: 75; 2000: 20). Y continúa: "Ellos han acopiado grandes cantidades en su granero, pero la ciencia puede decirles 'mañana exigiré tu vida', porque es ella la que decide el sentido que cada resultado particular debe tener dentro de la totalidad [ $i$ det Hele]" (Kierkegaard, 2011: 75; 2000: 20). Así, pues, la verdadera ciencia [Videnskab], según el autor de la carta, es aquella que abarca la totalidad, y el genuino investigador de la naturaleza es aquel "cuya especulación [Speculation] ha descubierto o se ha esforzado por descubrir aquel punto arquimédico [biint archimediske Punct] que no está en ninguna parte del mundo y desde el cual ha contemplado el todo [det Hele] y las particularidades [Enkelthederne] en su justa luz" (Kierkegaard, 2011: 75; 2000: 20-21). Esta clase de ciencia trata más de especulación y contemplación que de observación empírica, lo cual es necesario, desde luego, cuando su objeto principal es algo que no se encuentra "en 
ninguna parte del mundo". En Copenhague, continúa Kierkegaard (2011: 76; 2000: 21), existen tres científicos de este género; en este grupo incluye a Hans Christian Ørsted, el descubridor de las leyes del electromagnetismo y quizá el científico más importante, junto con Niels Bohr, en la historia de Dinamarca.

En el caso de la teología ocurre algo parecido. Aquí el autor se concentra en la figura del cristianismo, al que compara con un enorme coloso: "Lo llamo a propósito un enorme coloso porque, en efecto, tomado en su totalidad [ $i$ det Hele], implica muchas consecuencias y las partes singulares [det enkelte Dele] se han fundido con el correr de los siglos de forma tan estrecha que es difícil atacarlo" (Kierkegaard, 2011: 76; 2000: 21). Según el autor, hay en el cristianismo varios "puntos particulares [enkelte Puncter]" que deberían ponerse en duda; entonces "la totalidad [det Hele] asumiría una figura por completo distinta" (Kierkegaard, 2011: 77; 2000: 21-22).

Además de la revelación tal vez autobiográfica de una crisis religiosa con relación al cristianismo, este pasaje deja ver con claridad la insistencia de Kierkegaard en el binomio totalidad y particularidad. El supuesto principal del planteamiento es que las particularidades solo pueden comprenderse de forma correcta cuando son vistas bajo la luz de la totalidad. Todo indica que, hasta este momento - recordemos que la fecha de la carta, 1 de junio, es "antes" del viaje a Gilleleje-, Kierkegaard es un partidario entusiasta de la visión sistemática y especulativa propuesta por Heiberg, quien a su vez cree estar basándose en Hegel. Incluso para descubrir cuál es el propio destino individual, es menester haber encontrado primero ese punto arquimédico, es decir, la visión integral de la totalidad y su relación con las partes. Después de todo, el individuo es también una parte dentro de este cosmos orgánico.

La carta en sentido estricto (es decir, sin la posdata) concluye con una nota al parecer autobiográfica acerca de cómo su padre lo presiona para que consiga el certificado de teología ${ }^{5}$. Al igual que al comienzo, se elogia la dicha del paleontólogo, Lund, quien ha encontrado en Brasil el lugar que le es propio en la vida (Kierkegaard, 2011: 78; 2000: 23).

\footnotetext{
5 Sería posible argumentar, por otro lado, que la figura paterna severa que se opone a los sueños románticos del hijo constituye también un lugar común literario. Piénsese en el caso ejemplar del padre de Wilhelm Meister, un funcionario que no quiere saber nada de la "misión teatral" de su hijo. El protagonista de la novela corta de Møller era también un estudiante de teología (al igual, por supuesto, que el mismo Møller).
} 


\section{VERDAD OBJETIVA Y VERDAD SUBJETIVA}

Al margen del cuerpo principal de la carta, Kierkegaard añade una nota en cuyas últimas líneas se lee lo siguiente:

Cuando advertimos la desigualdad de lugares y situaciones, entonces o bien con mirada envidiosa sentimos la falta de lo que les ese concedido a otros, o bien con nostalgia agradecida vemos cuánto de lo que nos es dado les está negado a los otros. Y ahora una fría filosofía nos explica la totalidad en virtud de una preexistencia, en vez de apreciarla como una infinita pintura de vida con su abigarrado juego de colores y sus innumerables matices. (2011: 79; 2000: 23)

Esta observación marginal acerca de una "fría filosofía" que pretende explicarlo todo desde la distancia, ahorrándose la tarea de sumergirse en las vicisitudes de la vida real, parece anunciarnos la peripecia del diario de Gilleleje, el cambio de enfoque. Tras despedirse de su interlocutor, Kierkegaard inicia una nueva sección que, me gustaría argumentar, podría considerarse como una especie de posdata. Por un lado, Kierkegaard incluye esta segunda sección -junto con un conjunto de notas marginales, una de las cuales acabamos de citar- en la misma entrada que la car$\mathrm{ta}^{6}$. Por otro lado, se alude de forma directa a lo dicho en la carta y se intenta establecer un contraste entre el punto de vista de aquel momento y el "actual". El nuevo pasaje está fechado en Gilleleje el 1 de agosto, supuestamente dos meses después de la carta. Aunque no es claro su el autor se dirige una vez más al paleontólogo o a un lector imaginario, en las primeras líneas se nos avisa que ha tenido lugar un cambio de perspectiva: "Tal como intenté mostrar en lo anterior, así veía yo las cosas. Sin embargo, cuando quiero poner en claro mi vida, todo me parece de otra manera" (Kierkegaard, 2011: 79; 2000: 23).

Kierkegaard menciona una vez más el tema del desarrollo de la primera juventud, refiriéndose en esta ocasión a sí mismo. En un primer momento, señala, ha permanecido en un estado de pasividad, apenas distinguiéndose de su entorno. Pero entonces ha ingresado en un estado de "desasosiego", la duda, algo semejante a un "acceso de fiebre después del alivio del agua fría" (Kierkegaard, 2011: 79; 2000: 24). A continuación, nos encontramos con ese pasaje que los estudiosos de Kierkegaard

6 Es decir, la entrada 12 del cuaderno AA. En cambio, Peter Andreas Heiberg y Viktor Kuhr (1909), los editores de los Papirer, separan los dos escritos: la carta es la entrada 72 y la posdata es la entrada 75. Por este motivo, algunos comentadores ha considerado como separado algo que Kierkegaard concibió como unido. 
conocen muy bien y que se ha convertido en una especie de manifiesto existencialista:

Lo que necesito es ver con claridad qué debo hacer y no qué debo conocer, a no ser en la medida en que el conocimiento debe preceder a cualquier acción. Se trata de entender mi destino [Bestemmelse], de ver lo que la divinidad [Guddomen] quiere que yo haga. Lo que importa es encontrar una verdad [en Sandhed] que sea verdad para mí, encontrar esa idea [den Idee] por la cual querer vivir y morir. ¿De qué me serviría, entonces, encontrar la así llamada verdad objetiva [objectiv Sandhed], esforzarme con los sistemas de los filósofos y poder, cuando se me exigiera, pasar revista de ellos, mostrar las inconsecuencias de cada cuestión particular? (Kierkegaard, 2011: 80; 2000: 24. Las cursivas son de Kierkegaard)

En los párrafos siguientes, Kierkegaard insistirá en dos nociones fundamentales. En primer lugar, que la verdad debe tener un vínculo con la existencia del individuo; dicho de otro modo, su carácter ha de ser práctico, no teórico (lo importante es el qué debo hacer, no el qué debo conocer). En segundo lugar, que el conocimiento objetivo no puede cumplir esta función de forma adecuada. En términos generales, podría afirmarse correctamente que esta es una de las intuiciones principales que Kierkegaard continuará desarrollando a lo largo de su obra. A primera vista, parecería, en efecto, que Kierkegaard finalmente se ha rebelado en contra de las visiones sistemáticas de pensadores como Heiberg o Hegel, convirtiéndose en el campeón de la verdad subjetiva con el que ha alcanzado la celebridad. Es evidente también que el debate entre universalidad e individualidad se ha volcado por fin, al menos en este pasaje, a favor de la última.

No obstante, eso no significa que Kierkegaard haya abandonado de repente el esquema sistemático sobre el cual ha desarrollado sus ideas hasta este momento. Es importante observar que vuelve a utilizar la expresión "destino" y que, en vez de referirse al Dios [Guden], habla de la divinidad [Guddomen]. Más adelante escribe que "la raíz más profunda de mi existencia" se encuentra en "el interior de lo divino [ $i$ det Guddomelige], unido a ella aunque el mundo entero se derrumbara" (Kierkegaard, 2011: 81; 2000: 26). Aparece tal vez un sesgo panteísta en la frase anterior, donde "lo divino" parece aludir no tanto a un dios personal, sino a la totalidad [det Hele]. Esto parece confirmarse en el siguiente pasaje:

Lo que importa es la acción interior del hombre, el lado divino del hombre y no la cantidad de sus conocimientos, que sin duda serán alcanzados, pero no como agregados casuales o como una serie de particularidades [en Rakke af Enkeltheder] puestas una al lado de la otra, sin un sistema [uden et 
System], sin un punto focal en el cual se unan todos los radios. (Kierkegaard, 2011: 81; 2000: 26)

Dicho punto focal, el punto arquimédico al que ya varias veces se ha referido, tiene como fundamento una visión sistemática del todo. Lo anterior podría parecer incongruente, en especial si tomamos como referencia el pensamiento posterior de Kierkegaard, donde las nociones de existencia individual y sistema suelen plantearse como términos excluyentes. Así, por ejemplo, hay una sección entera del Postscriptum titulada "No es posible tener un sistema de la existencia" (Kierkegaard, 2008; 2002). No obstante, en este momento las premisas son distintas. En un contexto literario, la visión integral a la que aspira la Bildungsroman y, de un modo más específico, el proyecto dramático de Heiberg, no tiene como meta llegar a un estado de contemplación abstracta, sino transformar la vida del individuo. En última instancia, el héroe de la novela busca comprender el mundo para así comprenderse a sí mismo. En este sentido, verdad subjetiva y sistema son nociones complementarias.

Desde mi punto de vista, el "gran descubrimiento" que Kierkegaard intenta exponer en esta posdata reside no tanto en la primacía de la verdad subjetiva -es decir, que el conocimiento sistemático debe estar orientado a la vida práctica, al qué debo bacer y no al qué debo conocer-, sino en la forma en que se llega a dicha verdad. Es notorio que en esta entrada Kierkegaard se describe a sí mismo como una especie de Fausto (algo que se anticipaba en la carta a Lund) que ha intentado de forma infructuosa alcanzar la sabiduría a través de elementos externos:

Y así como he intentado anclarme en lo más profundo del conocimiento, de igual modo lo intenté en vano en el mar ilimitado de las diversiones. He sentido el poder casi irresistible con el que una diversión le da la mano a la otra, esa especie de entusiasmo artificial que es capaz de producir. He probado los frutos del árbol del conocimiento y a menudo me alegré de su sabor. Pero esa alegría duró solo el instante del conocimiento y su paso no me dejó ninguna marca más profunda. (2011: 81; 2000: 26)

Al percatarse de la vanidad de todo, Kierkegaard (2011: 82; 2000: 27) se decide, por último, a buscar dentro de sí mismo: "En primer lugar, uno debe aprender a conocerse a sí mismo antes de conocer cualquier cosa". Y concluye: "Solo entonces seré capaz, como el niño que al realizar su primera acción consciente se llama a sí mismo 'yo', entonces seré capaz de llamarme 'yo' en un sentido más profundo" (Kierkegaard, 2011: 84; 2000: 30). 


\section{CONCLUSIÓN}

$\mathrm{Al}$ igual que en la mayoría de los escritos tempranos de Kierkegaard, en el diario de Gilleleje se echa de menos un adecuado desarrollo conceptual de las ideas que su autor desea exponer. En lugar de eso, el lector se encuentra con una abundancia de metáforas, discursos hiperbólicos y otros recursos literarios para crear imágenes, no conceptos, en las que insistirá una y otra vez a lo largo del diario. Lo anterior tiene sentido, desde luego, si consideramos el diario como una construcción literaria, ficticia o histórica, y no como un discurso filosófico. Téngase también en cuenta que, tratándose de un diario íntimo, lo primero resulta más razonable que lo segundo.

Pero incluso si hemos de conformarnos con tal exposición narrativa, sería desafortunado si, a pesar de todo, no fuéramos capaces de llegar a ciertas conclusiones, al menos en algunos puntos principales. La intuición fundamental de Kierkegaard, la necesidad de encontrar el famoso "punto arquimédico", se desarrolla tomando como referente la moda literaria de la época, la de la novela corta que toma como modelo la Bildungsroman. En el diario de Gilleleje observamos primero al héroe que sale al mundo en busca de ese punto arquimédico. Al final, se nos revela que el mundo no le ha proporcionado las respuestas que esperaba y, en consecuencia, el protagonista se retrae sobre sí mismo. Enfrentado a la duda, el denominado problema fáustico, el héroe puede sucumbir y entonces vuelve a un estado pasivo, o alcanza un nivel superior de conciencia en el que se percata de que la clave de su desarrollo existencial es la búsqueda y el descubrimiento de una verdad subjetiva. Podría argumentarse, de hecho, que este itinerario es el mismo de la obra de Kierkegaard. Es el escándalo al que se enfrenta el cristiano antes de acceder a la fe genuina, como se describe en libros como Temor y temblor o Ejercitación en el cristianismo, o la desesperación en la que se hunde el libertino frente a la posibilidad de ingresar al mundo ético de la vida en matrimonio, como se ilustra de forma poética en Etapas en el camino de la vida o La repetición. El escritor danés intentará mostrarnos que, en el escenario más grande de la existencia real, este es el itinerario en la vida de todo individuo.

\section{REFERENCIAS}

Barfod, H. P. (1869). Af Soren Kierkegaards Efterladte Papirer. 1833-1843. Copenhague: C. A. Reitzels Forlag.

Brunn, S. \& Knudsen, J. (2000). Tekstredegørelse til Journalen AA. En N. J. Cappelørn, J. Garff, J. Knudsen, J. Kondrup, A. McKinnon \& F. H. 
Mortensen (Eds.), Soren Kierkegaards Skrifter. Bind 17 og K17. Journalerne AA, $B B, C C, D D$. Copenhague: Gads Forlag.

Fenger, H. (1980). Kierkegaard. The Myths and Their Origins (G. C. Schoolfield, trad.). New Haven y London: Yale University Press.

Garff, J. (2003). What did I find? Not my I: On Kierkegaard's Journals and the Pseudonymous Autobiography. En N. J. Cappelørn, R. Crouter, T. Jørgensen \& C. Osthövener (Eds.), Kierkegaard und Scbleiermacher. Subjektivität und Wabrbeit (pp. 355-370), Berlín y Nueva York: Walter de Gruyter.

Heiberg, J. L. (1862). Autobiografiske Fragmenter. En Prosaiske Skrifter (vol. 11, pp. 485-504), Copenhague: C. A. Reitzel.

Heiberg, J. L. (1833). Om Philosophiens Betydning for den Nwvarende Tid. Copenhague: C. A. Reitzel.

Heiberg, J. L. (1861). Schillers og Göthes Brevvexling. En Prosaiske Fragmenter (vol. 5, pp. 213-326), Copenhague: C. A. Reitzel.

Kierkegaard, S. (2000). Soren Kierkegaards Skrifter. Bind 17 og K17. Journalerne AA, $B B, C C, D D$. Copenhague: Gads Forlag.

Kierkegaard, S. (2002). Soren Kierkegaards Skrifter. Bind 7 og K7. Afsluttende widenskabelig Efterskrift. Copenhague: Gads Forlag.

Kierkegaard, S. (2008). Postscriptum no cientifico y definitivo a Migajas filosóficas (N. Bravo, trad.). Ciudad de México: Universidad Iberoamericana.

Kierkegaard, S. (2011). Los primeros diarios. Volumen I. 1934-1937 (M. Binetti, trad.). Ciudad de México: Universidad Iberoamericana.

Kuhr, V. \& Heiberg, P. A. (1909). Soren Kierkegaards Papirer. Bind 1. Copenhague: Gyldendalske Boghandel Nordisk Forlag.

Nun, K. \& Stewart, J. (2008). Goethe: A German Classic through the Filter of the Danish Golden Age. En J. Stewart (Ed.), Kierkegaard and his German Contemporaries. Tome III: Literature and Aesthetics (vol. 6, pp. 51-96), Farnham y Burlington: Ashgate.

Rojas, F. (2016). La angustia: un camino del hombre hacia lo divino. Ideas $y$ Valores, (65), 137-154.

Thulstrup, N. (1953). Breve og Akstykker vedrorende Soren Kierkegaard. Copenhague: Munskgaard. 